\title{
CHANGES IN THE POLYPEPTIDE COMPOSITION OF INTERNAL MEMBRANES OF BARLEY PLASTIDS DURING GREENING
}

\author{
by \\ GUNILLA HØYER-HANSEN \\ and \\ DAVID J. SIMPSON \\ Department of Physiology, Carlsberg Laboratory \\ Gamle Carlsberg Vej 10, DK-2500 Copenhagen, Valby

\begin{abstract}
Keywords: Chlorophyll-protein complexes, chloroplast thylakoids, etioplast membranes, electron microscopy, membrane isolation and purification, SDS-gel electrophoresis
\end{abstract}

\begin{abstract}
A method is described for obtaining good yields of purified internal membranes of plastids from greening barley seedlings. The procedure is suitable, without modification, for isolating intact plastids from etiolated seedlings and all early stages of greening. Electron microscopy was used to identify the types of contaminants present in preparations obtained by different methods, and to assess the degree of contamination in purified membranes. Gel electrophoresis of the sodium dodecyl sulphate-solubilised membrane polypeptides established that the proteins pelleted during flotation were a major component of unpurified membrane preparations from etioplasts and plastids greened for 9 hours or less. The polypeptide composition of purified etioplast membranes consisted of 35 bands. At least 15 of these disappeared during subsequent greening. After only 3 hours of illumination, the internal membranes contained almost all of the 43 polypeptides present in mature chloroplast thylakoids. The changes in polypeptide composition from $3-24 \mathrm{~h}$ were mainly quantitative in nature.
\end{abstract}

\section{INTRODUCTION}

In an earlier paper (6), the polypeptide composition of the internal membranes of wild-type barley etioplasts was compared with that of thylakoids isolated from chloroplasts. It was concluded in this, and other studies $(2,4,8,10$, 13 ), that certain prominent polypeptide bands present in chloroplast membrane patterns were absent or reduced in intensity in patterns of etioplast membranes. Conversely, other bands were found only in the polypeptide pattern of etioplast membranes.

The further analyses of the changes in thylakoid polypeptide patterns during greening of barley required an improved procedure for the purification of internal plastid membranes, 
especially those of etioplasts and young chloroplasts during the first 24 hours of greening. Etioplasts and greening plastids contain few internal membranes, which are less stable and less dense than chloroplast lamellar systems. They are therefore difficult to isolate in good yield and high purity.

The present communication reports a method for isolating good yields of highly pure, internal plastid membranes from etiolated and greening barley seedlings. The method is based on the procedure for isolating intact plastids from barley seedlings developed by KANNANGARA and GoUgH (7) followed by osmotic shock of the organelles and subsequent purification of the thylakoids by flotation in a sucrose gradient $(1,12)$. Electron microscopy is used to monitor the extent and nature of contamination of plastid membranes at different stages of purification. The high yield and purity achieved make it possible to detect changes in the level of many minor polypeptides during greening.

\section{MATERIALS AND METHODS}

\subsection{Plant material}

Barley seedlings (Hordeum vulgare L. cv. Svalöfs Bonus) were grown on tap water moistened vermiculite, in darkness at $20^{\circ} \mathrm{C}$ for 6 days. The seedlings were transferred to continuous light ( $1500 \operatorname{lux})$ at $20^{\circ}$ and plastids were isolated from seedlings greened for $0,3,6,9,12$ and $24 \mathrm{~h}$. The top $5-8 \mathrm{~cm}$ of pigmented leaves were harvested.

\subsection{Plastid isolation and preparation of membranes}

Isolation of the plastid internal membranes was carried out according to the flowsheet below:

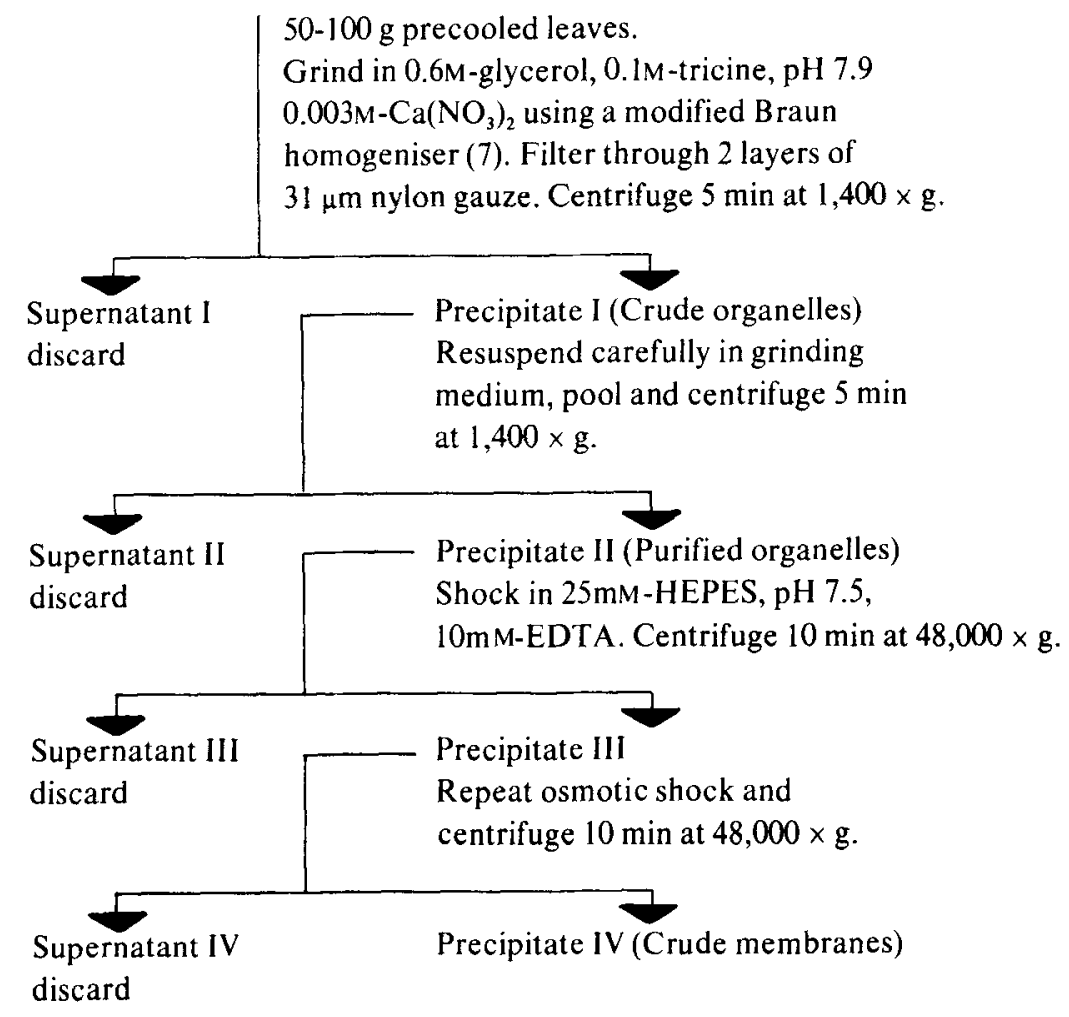

Abbreviations: $\mathrm{CF}_{1}$, coupling factor. CPI, chlorophyll-protein complex I. CPII, chlorophyll-protein complex II. HEPES, N-(2-hydroxyethyl)-piperazine-N'-2-ethane sulphonic acid. SDS, sodium dodecyl sulphate. 
Purification of the membranes was achieved by employing a modification of the flotation procedure of CHUA and BENNOUN (1). The precipitate IV was resuspended in $1.90 \mathrm{M}$ sucrose, 25mM-HEPES (pH 7.5), 5mM-EDTA, using a motordriven teflon pestle. To each centrifuge tube was added approximately $5 \mathrm{ml}$ of this suspension, which was overlayered with $5 \mathrm{ml}$ of $1.30 \mathrm{M}$-sucrose, 25mM-HEPES ( $\mathrm{pH} 7.5$ ), $5 \mathrm{mM}-\mathrm{EDTA}$. The tubes were topped up with 1.14m-sucrose, 25mM-HEPES (pH 7.5), 5mMEDTA and centrifuged at $4^{\circ} \mathrm{C}$ for $\mathrm{lh}$ at 140,000 $x \mathrm{~g}$ using an SW 40 rotor in a Beckman ultracentrifuge. The pigmented membranes that floated to the interface between $1.3 \mathrm{M}-/ 1.14 \mathrm{M}$ sucrose were collected with a syringe and washed in 25mM-HEPES (pH 7.5), $10 \mathrm{mM}$ EDTA, and resuspended in $0.05 \mathrm{M}-\mathrm{Na}_{2} \mathrm{CO}_{3}-$ $0.05 \mathrm{M}$-dithiothreitol before addition of SDS. All operations were done at $4^{\circ} \mathrm{C}$ or below.

\subsection{Gel electrophoresis}

Gel electrophoresis was performed using the conditions described by CHUA and BENNOUN (1).

\subsection{Electron microscopy}

An aliquot $(0.2 \mathrm{ml})$ of the purified organelle pellet (precipitate II) resuspended in grinding medium, was collected with a Pasteur pipette and fixed for $\mathrm{lh}$ in $2 \mathrm{ml}$ of $2 \%$ glutaraldehyde in grinding medium. This was pelleted by gentle centrifugation and all subsequent operations were carried out with this pellet. Samples of the purified membrane fractions were taken by plunging a Pasteur pipette into the appropriate pelleted material and extruding the cylinder of collected material into a $1 \%$ solution of glutaraldehyde in $0.3 \mathrm{M}$-sucrose, $0.05 \mathrm{M}$-sodium phosphate buffer ( $\mathrm{pH} 7.3$ ), 0.01M-KC1. This material was also kept intact during the rest of the fixation schedule for ease of handling.

Samples were then washed three times in $0.05 \mathrm{M}$-sodium phosphate buffer $(\mathrm{pH} 7.3)$ and fixed for $\mathrm{lh}$ in $1 \% \mathrm{OsO}_{4}$ in $0.05 \mathrm{M}$-sodium phosphate buffer ( $\mathrm{pH}$ 7.3). After several washes in distilled water, the organelle pellets were stained in bloc with $2 \%$ uranyl acetate for 1 h, then all samples were dehydrated in a graded ethanol series and infiltrated and embedded in Spurr's resin (17). Thin sections were cut so as to extend from the bottom of the organelle pellet to the top to ensure that a representative sample was examined. Sections were picked up on $3 \mathrm{~mm}$ slotted grids and post-stained for 30 $\min$ at $60^{\circ} \mathrm{C}$ with $5 \%$ uranyl acetate followed by $30 \mathrm{~min}$ at $20^{\circ} \mathrm{C}$ with REYNOLDS' lead citrate (14) in an automatic staining apparatus. Purified membrane sections were stained for $30 \mathrm{~min}$ at $20^{\circ} \mathrm{C}$ in $1 \% \mathrm{KMnO}_{4}$ instead of lead citrate to enhance contrast. Grids were examined in a Siemens Elmiskop 102, operated at $80 \mathrm{kV}$.

\section{RESULTS}

When preparations of isolated plastids were examined by electron microscopy, it was realised that methods suitable for obtaining relatively pure chloroplast thylakoids were not suitable for the isolation of internal plastid membranes from etiolated and greening barley seedlings. Mature chloroplasts and naked lamellar systems retained their integrity with isolation procedures that disrupted etioplasts and plastids in early stages of greening. The inevitably lower yields of immature plastids, due to breakage during isolation, meant that the non-plastid protein that constituted a minor contaminant of chloroplasts, became a significant, if not major, component of the plastid pellet.

Preliminary experiments in isolating etioplasts and plastids from etiolated tissue greened for $3 \mathrm{~h}$, indicated that the major contaminant of the organelle pellet was nuclear material as judged by light- and electronmicroscopy. An attempt was made to increase the yield of plastid membranes by centrifuging for $10 \mathrm{~min}$ at $12,000 \times \mathrm{g}$ to pellet isolated prolamellar bodies and other internal membranes, as well as intact plastids. Examination of a representative sample of this material by electron microscopy revealed that the treatment increased the pellet size mainly due to increased sedimentation of mitochondria, as well as rough endoplasmic reticulum and other membranes of indeterminate origin. 


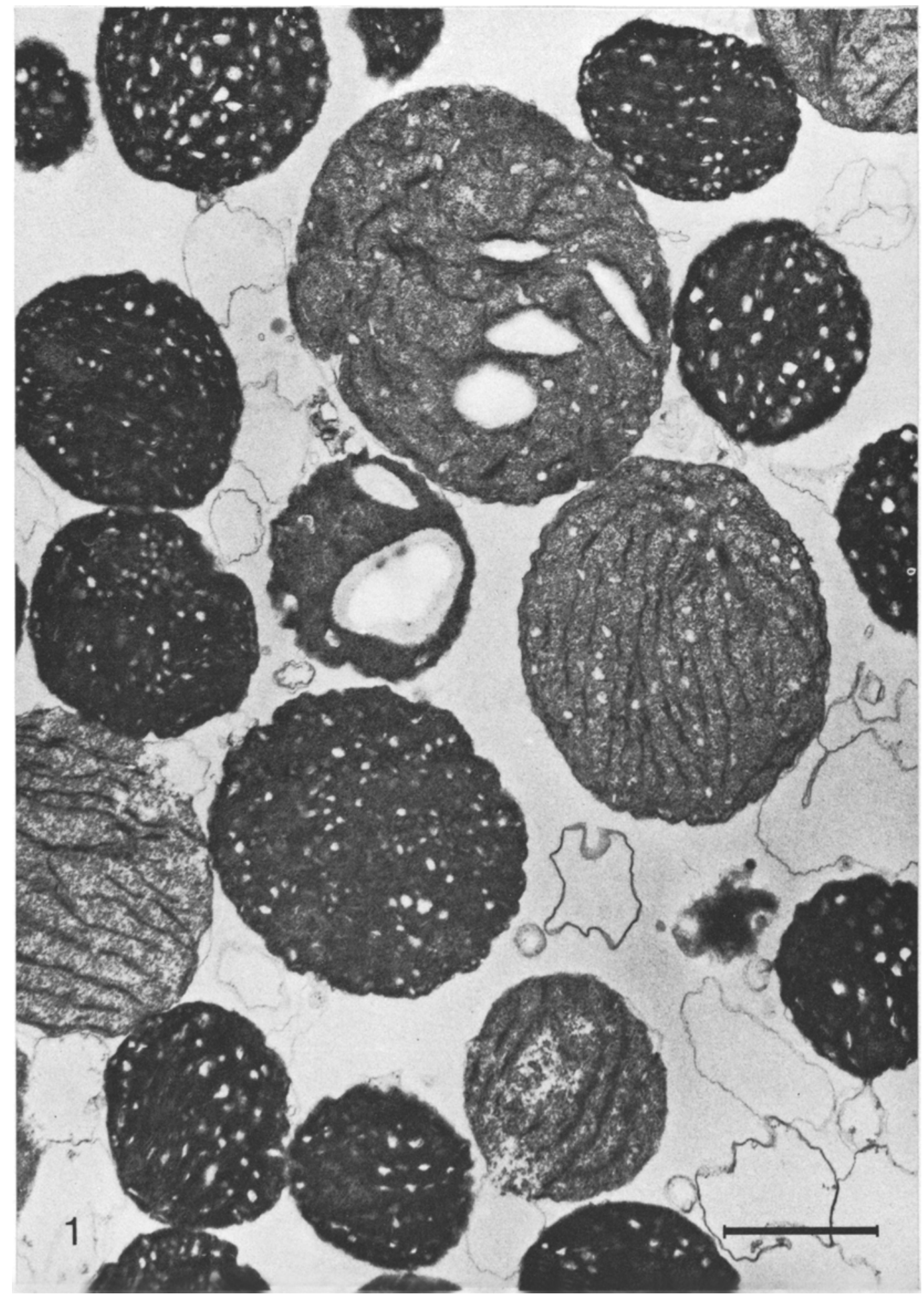

Figure 1. Electron micrograph of a representative field of the plastids of precipitate II, isolated from barley seedlings greened for $6 \mathrm{~h}$. The thylakoid vesiculation and heavy staining of the stroma of many plastids is probably due to the incorporation of glycerol in the fixative.

$\times 11,700(\mathrm{Bar}=2.0 \mu \mathrm{m})$. 


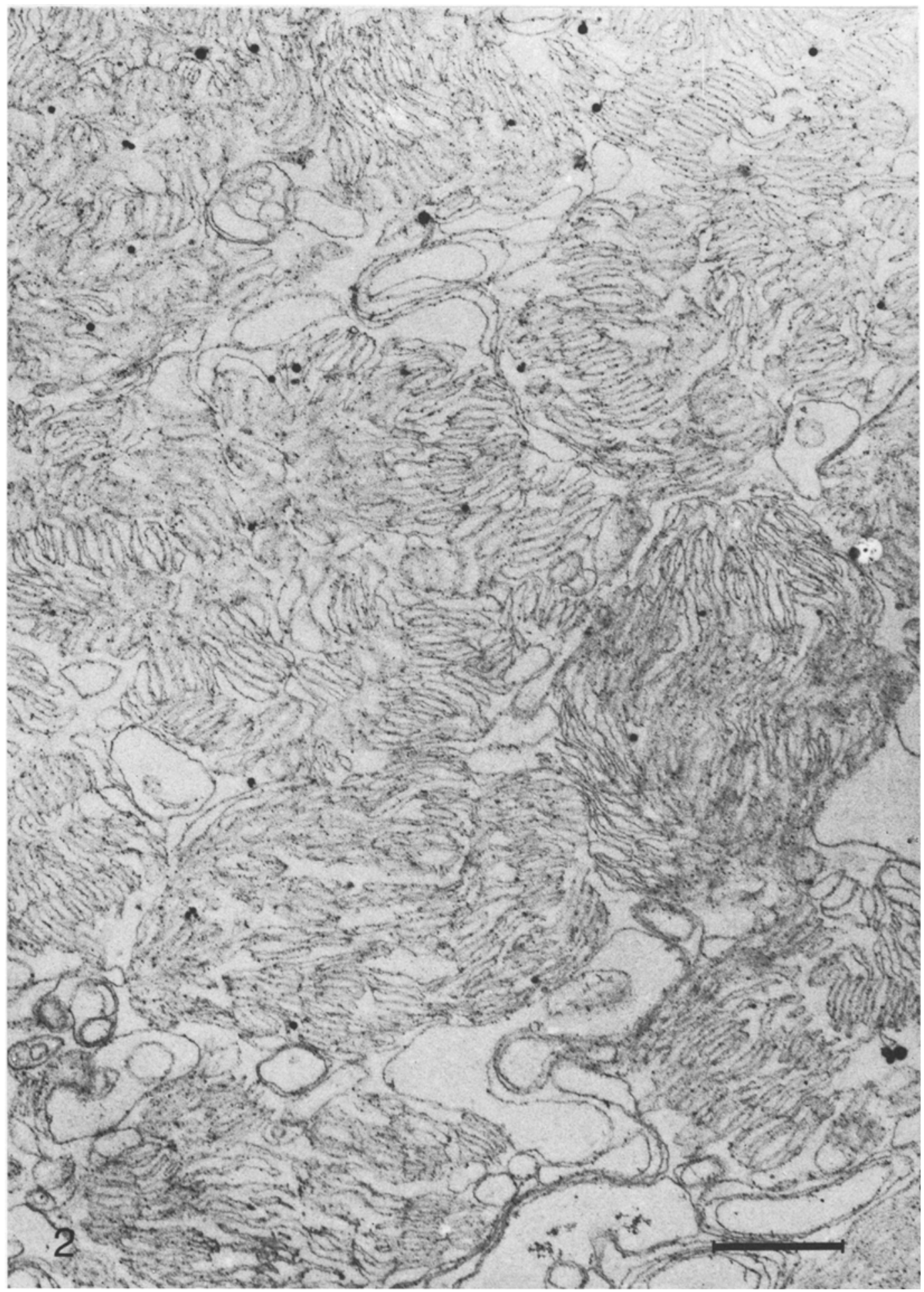

Figure 2. Micrograph of the purified membranes in the $C$ fraction obtained from seedlings greened for $24 \mathrm{~h}$, demonstrating the high purity of this fraction. The small particles associated with the thylakoids are coupling factor molecules visualised by in bloc staining with uranyl acetate.

$\times 9,900(\mathrm{Bar}=2.0 \mu \mathrm{m})$. 
The flotation technique of CHUA and BENNOUN (1) using a discontinuous sucrose gradient was adopted to separate internal plastid membranes, obtained after osmotically shocking the organelle pellet, from nuclear material and foreign membranes. After ultracentrifugation $(\mathrm{h}$ at $140,000 \times \mathrm{g})$, the original material was resolved into a pellet and two pigmented bands, one at the $1.9 \mathrm{M}-11.3 \mathrm{M}$ sucrose interface, and the other at the $1.3 \mathrm{M}-/$ $0.2 \mathrm{M}$-sucrose interface. The pellet was found by electron microscopy to consist mainly of nuclear material, starch, and micro-organisms. The lower band of pigmented membranes contained some nuclear material as well as considerable numbers of mitochondria, which had survived the osmotic shock and centrifugation sufficiently well to be recognisable as such. This band from chloroplasts contained, in addition, relatively intact grana. The upper band appeared in all cases to be purer, with almost no nuclear material identifiable by electron microscopy, but was nevertheless contaminated with mitochondria, and also small pieces of cell wall.

The above results demonstrated that flotation could successfully remove nuclear and microbial proteins from internal plastid membranes, but was only partially effective in removing mitochondria. The presence of intact (although severely swollen) mitochondria after flotation indicated that as many of the mitochondria as possible should be removed before this step. The density of the top sucrose layer was increased to $1.14 \mathrm{M}$ to enable the separation of cell wall fragments and light membranes from thylakoids.

Etioplasts and chloroplasts were then isolated by several different methods designed to separate intact plastids from intact mitochondria by virtue of their different specific gravities. Bovine serum albumin $(0.1 \%)$ was added to the grinding medium to prevent the swelling of mitochondria (11). Although : $1.46 \mathrm{M}$-sucrose cushion reduced the contamination of the plastid pellet by mitochondria, yield: were low, and it was found that bovine serum albumin caused swelling and rupture of greening plastids, and was omitted in subsequent experiments.

The procedure described in the methods section was adopted for all further work. Glycerol $(0.6 \mathrm{M})$ was used as the osmoticum (7) and mitochondria separated from plastids by differential centrifugation. This was achieved by a relatively gentle initial centrifugation ( 5 $\min$ at $1,400 \times \mathrm{g}$ ), followed by resuspension of the pooled pellets in grinding medium and another $5 \mathrm{~min}$ spin at $1,400 \times \mathrm{g}$. The resulting pellet was osmotically shocked to remove soluble proteins, and the membranes purified by flotation.

The yields of plastid membranes progressively increased from $0-12 \mathrm{~h}$ of greening and remained constant from $12-24 \mathrm{~h}$. This was mainly due to a greater proportion of naked lamellar systems to intact plastids as greening time increased. The purified plastid pellet (precipitate II) was sampled at each stage of greening for electron microscopy, and in all cases was found to be remarkably free from mitochondrial contamination (Fig. 1). Nuclear material, starch and micro-organisms were present, but were readily removed during the procedure of membrane purification by flotation (Fig. 2). Glycerol in the grinding medium as well as in the fixative caused extensive vesiculation of the internal membranes of many etioplasts, and plastids of 3 and 6 h greened seedlings (Fig. 1). The strong contrast of the stroma in the majority of the plastids may be due to the osmoticum (18) or tricine since all plastid pellets were fixed in $2 \%$ glutaraldehyde added to the grinding medium.

Figure 3. Gel electrophoresis of the fractions obtained during the purification of greening barley thylakoids. A, $\mathrm{B}$, and $\mathrm{C}$ refer to the fractions obtained by flotation, A corresponding to the pellet, $\mathrm{B}$ to the $1.90 \mathrm{M}-11.30 \mathrm{M}-\mathrm{sucrose}$ band and $C$ to the $1.30 \mathrm{M}-11.14 \mathrm{M}$-sucrose band. The prominent polypeptides present in $\mathrm{A}$ and apparently absent in $C$ are attributed to nuclear material. The polypeptide pattern of the $40,000 \times \mathrm{g}$ pellet from the supernatant $\mathrm{I}$, containing mitochondria and other organelles, reveals that none of the polypeptides in the $C$ pattern can be derived from contamination by material in the supernatant. The pattern in $\mathrm{C}$ is considered to be that of highly purified barley thylakoids. 


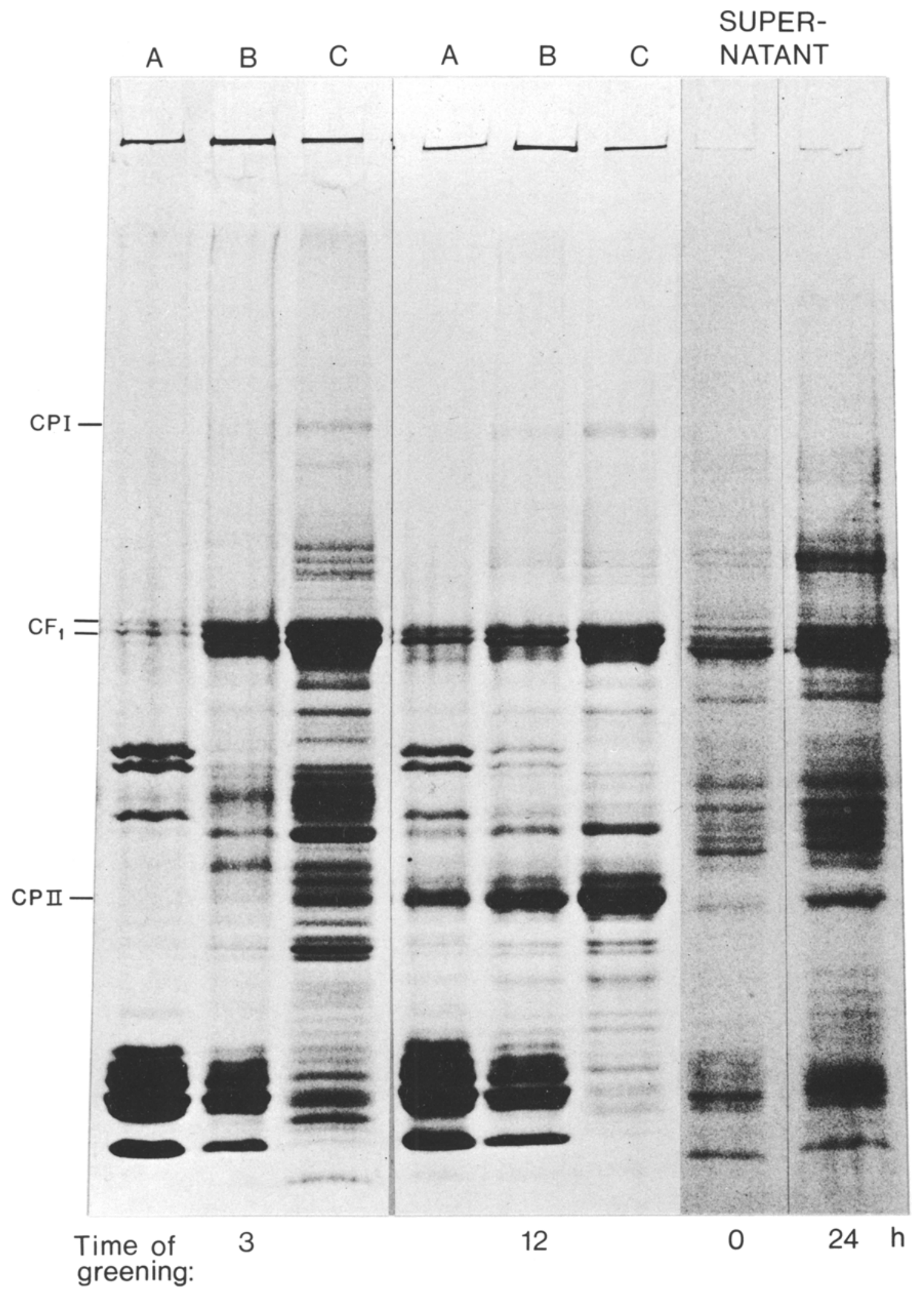


After substituting $1.14 \mathrm{M}$ - for $0.2 \mathrm{M}$-sucrose in the upper layer, the flotation procedure resulted in a pellet $(A)$, a pigmented band at the $1.90 \mathrm{M}-11.30 \mathrm{M}$-sucrose interface (B) and another pigmented band at the $1.30 \mathrm{M}-/ 1.14 \mathrm{M}$-sucrose interface $(C)$. An additional band of pigmented material was found on the surface of the uppermost layer, but only at 0 and $3 \mathrm{~h}$ of greening. The latter membranes were presumed to be derived from the prolamellar body and are not considered in this paper.

The gel electrophoretic analysis of the fractions obtained during plastid membrane purification correlate with the data obtained by electron microscopy. The polypeptide patterns of fractions $\mathrm{A}, \mathrm{B}$, and $\mathrm{C}$ for 3 and $12 \mathrm{hrs}$ of greening are presented in Figure 3 . At $3 \mathrm{~h}$ of greening the pellet $(A)$ contains nine prominent polypeptides which are absent or greatly reduced in the purified thylakoid fraction (C). These polypeptides are considered to be of nuclear origin, since the pellet was rich in nuclear material and since the gel pattern matches that obtained by O. SCHMIDT (personal communication) from isolated Vicia faba nuclei. These polypeptides also contaminate the $B$ fraction which is consistent with the morphologically observed presence of nuclear material. There are thylakoids in the pellet (A) as indicated by the presence of coupling factor $\left(\mathrm{CF}_{1}\right)$ subunits in the polypeptide patterns.

A larger proportion of thylakoids to nuclear material, as evidenced by the relatively prominent $\mathrm{CF}_{1}$ and chlorophyll-protein complex II (CPII) bands, is found in the pellet of $12 \mathrm{~h}$ greening. The thylakoid enrichment achieved in the $\mathrm{B}$ fraction and the thylakoid purification obtained in the $\mathrm{C}$ fraction is demonstrated by the increasing intensity of the $C F_{1}, C P I$, and CPll bands concomittant with the progressive disappearance of the nine bands of putative nuclear origin.
The polypeptide patterns of the $40,000 \times \mathrm{g}$ pellet of supernatant I from 0 and $24 \mathrm{~h}$ greened seedling leaves are included in Figure 3 in order to investigate the possible contribution of mitochondrial proteins to the gel pattern of fraction C. With exception of $\mathrm{CF}_{1}$ and CPII, the supernatant polypeptides do not contribute significantly to purified thylakoid pattern (C).

A comparison of the polypeptide composition of the purified internal plastid membranes (fraction $\mathrm{C}$ ) isolated from etiolated seedlings at different stages of greening is made in Figure 4. The pattern of the internal membrane polypeptides of etioplasts consisted of the 35 bands labelled in the figure as El to E35, and 6 low molecular weight polypeptides (unlabelled) which could result from a small residual nuclear contamination. After $24 \mathrm{~h}$ of greening, the thylakoid polypeptides were resolved into the 43 distinct bands labelled $\mathrm{Cl}$ to $\mathrm{C} 43$. The positions of CPI, CPII, $\mathrm{CF}_{1}$ subunits and reaction centre protein of photosystem II (RCPSII) are indicated. After only $3 \mathrm{~h}$ of greening, the polypeptide pattern of the internal membranes had changed dramatically towards the pattern of the $24 \mathrm{~h}$ greened thylakoids. A very obvious change in the patterns occurring between 3 and $24 \mathrm{~h}$ is the progressive increase in the intensity of CPII as well as the increase in the amount of $\mathrm{CPI}$ relative to coupling factor subunits.

The 15 etioplast membrane bands marked with an asterisk are reduced drastically during greening and cannot be detected in the $24 \mathrm{~h}$ pattern. The best example is the major etioplast polypeptide E20. Unequivocal examples of polypeptide bands that appear during greening are $\mathrm{Cl}, \mathrm{C} 2, \mathrm{C} 24$ and $\mathrm{C} 26$. In the pattern for three hours greening, 9 bands which cannot be seen after $24 \mathrm{~h}$ greening are indicated with a dash. While some of these correspond in position to etioplast bands, others do not. Possibly this is due to the reduction in the relative

Figure 4. Comparison of the polypeptide patterns of highly purified thylakoids of etioplasts (Oh) and plastids greened for 3 to $24 \mathrm{~h}$. The polypeptides readily visible in the gels have been numbered in order of increasing electrophoretic mobility for the thylakoids of the etioplasts as El to E35 and those for the chloroplast thylakoids in the same way from $\mathrm{Cl}$ to $\mathrm{C} 43$. For the pattern of $3 \mathrm{~h}$ greened plastids, polypeptides which are absent in the chloroplast pattern have been indicated. Chlorophyll-protein complex I (CPI) and II (CPII), coupling-factor $\left(C F_{1}\right)$ subunits and reaction centre protein of photosystem II (RCPSII) are identified. The etioplast polypeptides marked with an asterisk are those considered to disappear during greening. 


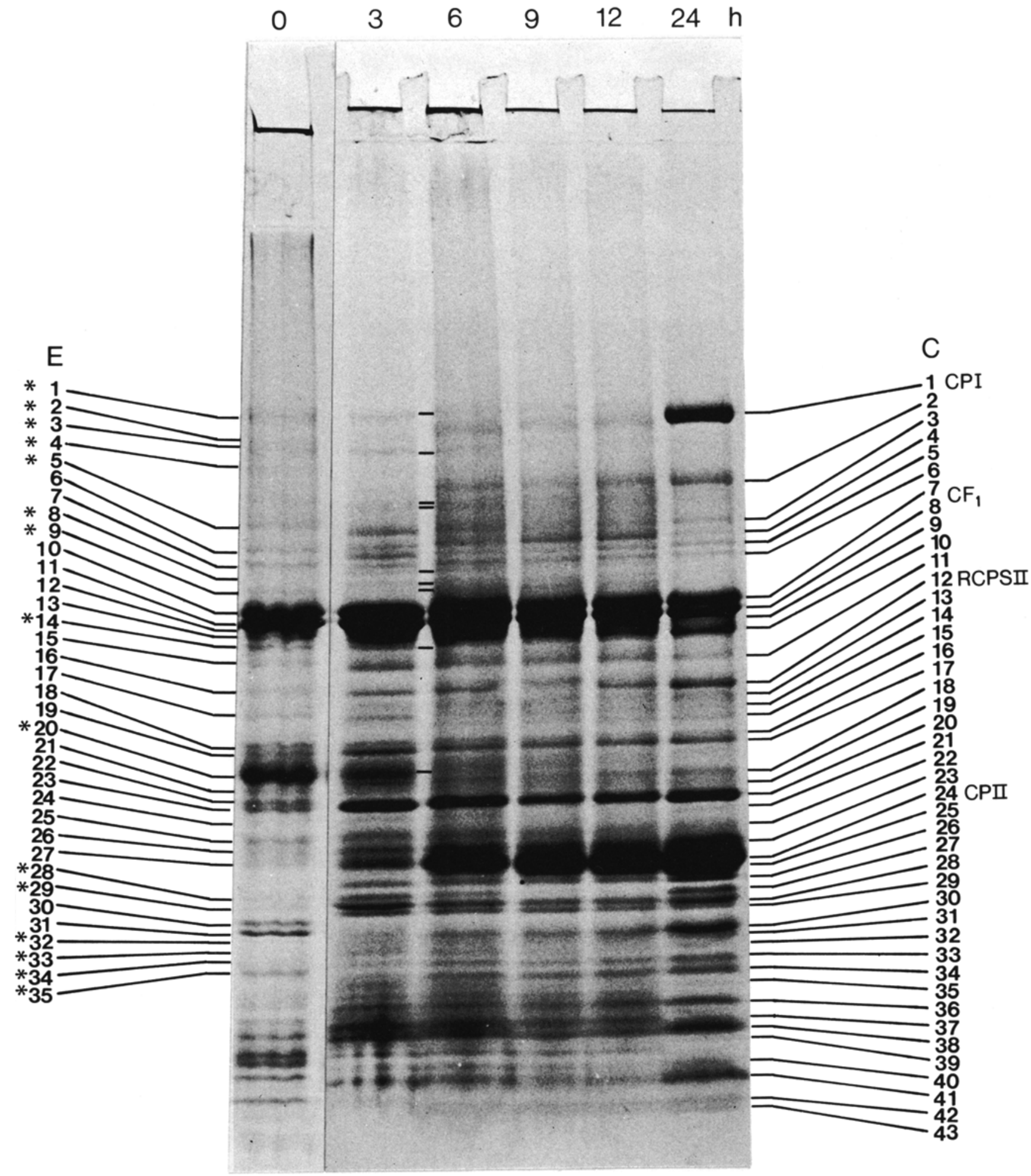


amounts of these latter polypeptides to the extent that during later stages of greening they can no longer be detected without overloading the gel.

The overall changes in the polypeptide patterns from internal membranes of etioplasts to thylakoids of $24 \mathrm{~h}$ greened plastids can be summarized as follows: At least 15 of the 35 etioplast bands disappear. To account for 43 bands in the chloroplasts, the appearance of at least 23 bands is required. To what extent this reflects de novo synthesis or changes in the electrophoretic mobility of pre-existing polypeptides requires further analyses, e.g., by immunoelectrophoresis employing monospecific antibodies.

\section{DISCUSSION}

The important feature of the procedure developed for the isolation of plastids from greening etiolated barley seedlings is that it can be used to obtain good yields of the internal plastid membranes free from the contamination present using previous methods $(6,9)$. The distinct doublet obtained in certain etioplast patterns by HøYER-HANSEN, MACHOLD and KAHN (6) and the group of heavily stained bands near the bottom of the gels in both etioplast and mutant membrane patterns $(6,9)$ must now be considered as contaminants, a possibility which has already been discussed (9).

The isolation procedure can be used without modification to isolate intact plastids from the different stages of greening. This feature in combination with the good yield of plastids, ensures that precipitate II constitutes a representative of the tissue irrespective of the stage of greening. The detection of all chloroplast thylakoid polypeptides after only $3 \mathrm{~h}$ of greening is attributable to this improved yield and purification. In the first experiments, using procedures like those employed in (6), membranes of the more stable etioplasts from lower parts of the leaves (cf. 15) were selectively isolated and the dramatic change in polypeptide patterns was not observed until after $6 \mathrm{~h}$ of greening.
The present results demonstrate that the etioplast internal membranes have a complex polypeptide composition although, in agreement with eariier results $(2,4,6,8,10,13)$, they lack certain of the polypeptides present in chloroplast thylakoids. The appearance of the proteins found in chloroplast thylakoids within $3 \mathrm{~h}$ of greening is consistent with the appearance of complete photosynthetic ability within this time $(3,5,16)$. The progressive increase in the amount of chlorophyll-protein complex II between 3 and $24 \mathrm{~h}$ in barley parallels the increase in photosynthetic unit size as reported by HENNINGSEN and BOARDMAN (5).

\section{ACKNOWLEDGEMENTS}

We wish to thank Dr. N.-H. CHUA for stimulating discussions and helpful advice. We are grateful to JEAN SAGE and ANN-SOFI STEINHOLTZ for providing technical assistance. Financial support was provided by EEC Contract 029-76-ES DK, Solar Energy Program and by US PHS, National Institutes of Health (GM22051) to Professor D. von Wettstein.

\section{REFERENCES}

1. Chua, N.-H. \& P. Bennoun: Thylakoid membrane polypeptides of Chlamydomonas reinhardtii: Wild-type and mutant strains deficient in photosystem II reaction center. Proc. Nat. Acad. Sci., USA 72, 2175-2179(1975)

2. Совв, A.H. \& A.R. Wellburn: Developmental changes in the levels of SDS-extractable polypeptides during plastid morphogenesis. Planta 114, 131-142 (1973)

3. Egneus, H., G. Sellden \& L. Andersson: Appearance and development of $P 700$ oxidation and photosystem I activity in etio-chloroplasts prepared from greening barley leaves. Planta 133, 47-52 (1976)

4. Forger, J.M. III \& L. Bogorad: Steps in the acquisition of photosynthetic competence by plastids of maize. Plant Physiol. 52, 491-497 (1973)

5. Henningsen, K.W.\& N.K. Boardman: Development of photochemical activity and the appearance of the high potential form of cytochrome b-559 in greening barley seedlings. Plant Physiol. 51, 1117-1126 (1973)

6. Høyer-Hansen, G., O. Machold \& A. Kahn: 
Polypeptide composition of internal membranes from barley etioplasts. Carlsberg Res. Commun. 41, 349-357 (1976)

7. Kannangara, C.G. \& S. Gough: $\delta$ aminolevulinic acid synthesis by isolated barley plastids. Carlsberg Res. Commun. In preparation.

8. LUTZ, C.: Biochemical and cytological examinations of chloroplast development 1 . The chemical characterization of prolamellar bodies from etioplasts of Avena sativa L. $Z$. Pflanzenphysiol. 75, 346-359 (1975)

9. Machold, O.\& G. Høyer-Hansen: Polypeptide composition of thylakoids from viridis and xantha mutants in barley. Carlsberg Res. Commun. 41, 359-366 (1976)

10. NiELSEN, N.C.: Electrophoretic characterization of membrane proteins during chloroplast development in barley. Eur. J. Biochem. 50,611$623(1975)$

11. Nishimura, M., D. Graham \& T. Akazawa: Isolation of intact chloroplasts and other cell organelles from spinach leaf protoplasts. Plant Physiol. 58, 309-314 (1976)

12. Petrocellis, B. de, P. Siekevitz \& G.E. Palade: Changes in chemical composition of thylakoid membranes during greening of the $y-I$ mutant of Chlamydomonas reinhardi. J. Cell Biol. 44, 618-634 (1970)

13. Phung nhu hung, S., R. Remy \& A. Moyse: Cytochromes and lamellar proteins of greening barley etioplasts. In: Proc. 2nd Int. Congr. Photosynthesis. G. Forti, M. Avron and B.A. Melandri, eds. Junk, The Hague pp. 2407-2415 (1971)

14. REYNOLDS, E.S.: The use of lead citrate at high $\mathrm{pH}$ as an electrondense stain in electron microscopy. J. Cell Biol. 17, 208.212 (1963)

15. Robertson, D. \& W.M. Laetsch: Structure and function of developing barley plastids. Plant Physiol. 56, 148-159 (1974)

16. Sellden, G. \& E. Selstam: Changes in chloroplast lipids during the development of photosynthetic activity in barley etiochloroplasts. Physiol. Plant. 37, 35-41 (1976)

17. SPURR, A.R.: A low viscosity epoxy resin embedding medium for electron microscopy. J. Ultrastruct. Res. 26, 31-43(1969)

18. Wellburn, A.R., P.H. Quall \& B.E.S. Gunning: Examination of ribosome-like particles in isolated prolamellar bodies. Planta 134, 45-52 (1977) 